\title{
Stage I Small Intestinal Gastrointestinal Stromal Tumor
}

National Cancer Institute

\section{Source}

National Cancer Institute. Stage I Small Intestinal Gastrointestinal Stromal Tumor. NCI

Thesaurus. Code C87831.

Stage I includes: T1 or T2, N0, M0, Mitotic rate: Low. T1: Tumor $2 \mathrm{~cm}$ or less in greatest dimension. T2: T umor more than $2 \mathrm{~cm}$, but not more than $5 \mathrm{~cm}$, in greatest dimension. NO: No regional lymph node metastasis. MO: No distant metastasis. (AJCC 7th ed.) 